\title{
Using focus groups to enhance student voice: a work-in-progress exploration of student learning experiences in large classes
}

\author{
Caitlin C. Finlayson, University of Mary Washington
}

\begin{abstract}
While course evaluations are traditionally used to gauge teaching effectiveness and provide an outlet for student voice, this metric does not integrate students as collective partners in the teaching and learning process. In promoting a shared learning experience between teachers and students, this project uses a focus group approach to solicit student feedback and ideas, and disseminate the results to faculty. This paper explores the results of a qualitative pilot focus group study related to student engagement in large classes and demonstrates that a focus group approach is an effective and empowering way to prioritise student voice.
\end{abstract}

Keywords: Focus groups; student engagement; reflective teaching

\section{Introduction}

The shared creation of the learning experience

Universities often promote a vision of students and faculty sharing in the creation of the teaching and learning experience. Too often, though, reflection on classroom instruction comes only at the end of the semester in the form of a course evaluation. In a large class in particular, students rarely have an opportunity to shape the classroom experience. While it would be ideal if all classes could be taught in small settings, the reality of general education requirements, class demands for majors, and staffing constraints means many students, at some point during their college career, will take a course with a large class size. Although these large classes do have a certain set of challenges, there are unique opportunities for learning as well. A larger class often means a more diverse class, for instance, and this wide array of life experiences can provide for very meaningful discussions. This work in progress paper explores how a student-driven focus group could be effectively utilised as a tool for incorporating student perspectives into such classes and to provide students with an empowering venue to express their ideas.

\section{Context}

\section{The Center for Teaching Excellence and Innovation at the University of Mary Washington}

The University of Mary Washington's Center for Teaching Excellence and Innovation provides support for faculty members seeking to enhance their teaching and engage with students in innovative and meaningful ways. One such venue of support is the Center for Teaching Excellence and Innovation's Meaningful Student Learning Micro Grant which is aimed at supporting projects that develop innovative teaching strategies and provide opportunities for 
student engagements. This project was funded as part of this grant program and sought to promote the University's mission to be 'a place where faculty, students, and staff share [emphasis added] in the creation and exploration of knowledge' (University of Mary Washington, 2010).

\section{Approaches to Incorporating Student Voice}

One of the most common methods for soliciting student feedback comes at the end of the semester in the form of a course evaluation. Marsh (1984) explored the effectiveness of course evaluations in terms of their reliability, validity, and usefulness and found that course evaluations were indeed reliable and were generally unaffected by various potential biases (Marsh 1984). Williams and Ceci (1997) and Wachtel (1998) later explored what factors might influence student ratings of a course. These approaches, while useful in critically examining course evaluations from a research perspective, pay no attention to how effective course evaluations are at providing an opportunity for students to shape the learning process. Little and Williams (2010) note that there is a tension between an understanding of students as 'consumers' and students as 'members of a learning community,' sharing in the production of knowledge (p.12). Research on the notion of student as partners in education is expanding, however, including work by Fluckiger et al. (2010) on collaborative student assessment methods and a project by Giles et al. (2004) which allowed students to plan and implement their own course evaluations.

Focus groups represent one way faculty can more effectively enhance student voice. As Breen (2006) explores, focus groups can be 'a rewarding learning experience [for participants]' (p.473). For students, focus groups provide a meaningful way for faculty to gain new instructional ideas, but also to engage students in a learning experience of their own. This approach to incorporating student voice also addresses some of the concerns discussed by Fielding (2001), allowing students to speak about their needs and innovative ideas in an empowering way and then providing a venue for faculty to truly listen. Focus groups further allow students to have a dialogue with each other (Hendershott \& Wright, 1993), again an aspect of student engagement that is not promoted with traditional course evaluations. Unlike end-ofsemester course evaluations, focus groups also provide students a sense that faculty genuinely care, connecting with the Hawthorne Effect (see Hamilton et al., 2002), which states that when workers feel that their managers are concerned about their welfare, they feel more cohesive and are more productive. Student focus groups have been proven effective in evaluating teacher effectiveness (Kramer \& Pier, 1997) and have also been shown to be more informative than survey data when evaluating departmental curriculum (Hendershott \& Wright, 1993). Virtual focus groups have even been used to evaluate online courses, providing faculty with feedback that was used to revise online instruction (Fitzgerald \& Corazzo, 2013).

\section{Research Methods}

\section{Sample Group}

This pilot study was comprised of a series of small focus group interviews that were conducted with six student volunteers. These students were selected by the researcher on the basis that they had taken or were currently enrolled in a large class. All six student volunteers, who were each 
members of what was termed a 'Student Learning Committee', participated in each of the focus group meetings over the course of the semester. Students were continually reminded that they, along with the faculty member/researcher, were equal members of the Student Learning Committee, and as such their opinions and ideas were highly valued.

\section{Methods for Engaging Student Voice}

This work in progress discusses the findings from a series of three focus groups. Focus groups can be thought of an in-depth group interviews, and 'are used to generate interchange and debate between respondents' (Secor, 2010, p.1999). For this project, each focus group was semistructured, including only a broad, general theme for students to discuss. This was seen as an appropriate method of engaging student voice because it allowed the students freedom to elaborate on certain topics or move the discussion into areas that the researcher had not foreseen.

Every session had a different core theme:

- Session 1: What works and what doesn't in large classes?

- Session 2: Assignments and activities in large classes

- Session 3: What are the key points students want instructors to know?

After the three focus group sessions had been conducted, all six students participated in a roundtable discussion with interested faculty members. Here, students reviewed the key focus group findings, principally those discussed in session 3, and made themselves available for questions from faculty. Faculty members were also provided a handout which included notes from each of the three sessions.

\section{Results}

\section{Student Reflections on Large Classroom Engagement}

The student focus groups proved to be much more informative than findings from previous course evaluations, and although this represents a pilot study, several key themes emerged that have already influenced classroom instruction. Students consistently noted that, particularly in a large class, instructor excitement and enthusiasm mattered; an excited instructor makes the course material, regardless of the subject matter, exciting. They enjoyed it when instructors offered personal experiences and anecdotes to make the material more accessible, and also to build a connection with the instructor. A key problem they noted with large classes is that they are often lower-level, and by nature then often have less motivated students, either students just starting out in a major or students taking the course to fulfil general education requirements, requiring even more effort from an instructor to show passion about the subject matter. Students also commented that they appreciated when instructors tried new things, even if they didn't work. When instructors tried a new activity, students suggested that the instructor might simply acknowledge the newness or strangeness of it and then just go for it, and even this acknowledgement created a dialog with students and allowed them some insight into the teaching process. 
One point that students consistently discussed was the need for variety in large classes. Students appreciated large classes that incorporated technology, for instance, such as smart phone surveys or text responses. Students particularly enjoyed small group activities and opportunities to break up the large lecture class into smaller groups. They mentioned that they were often intimidated to answer questions in a large class, so they could confer with their classmates in a small group first before addressing the class at large. One student likened this to stretching before exercising. It became clear in talking with students over the course of the semester that community-building was essential in large classes. Students mentioned that if they had a sense that the instructor knew who they were and that they knew their classmates, they felt much more motivated to be an active learner. This community building can take time away from core instruction, but represents an important step toward increasing student engagement.

\section{Effectiveness of Focus Group Method}

Although this represents a pilot study, it is clear from the series of conversations with students, and the feedback from faculty after the roundtable discussion, that student focus groups provide an effective method to provide instructors with student perspectives on teaching and learning and allow students a hand in shaping the classroom experience. Students repeatedly commented at the conclusion of the project that they loved that faculty wanted to listen to them, and this type of activity can clearly be empowering for the students involved. There are some limitations to the focus group method, however. As Breen (2006) notes, focus groups are time-consuming, and it can be difficult to find a time when all participants can meet. In addition, when working with students in an instructor-led focus group, students might be hesitant to discuss professors in the same department as the researcher, or might only wish to discuss the researcher's own class in a favourable light. Focus group findings are also less generalisable than survey data given the small sample size, though the data is far richer. Despite these limitations, this pilot study demonstrates how a student focus group might be structured and that, even in a limited scale, can provide meaningful findings especially used in conjunction with other methods.

\section{Conclusions / Future Considerations}

While this pilot group represented a small sample of students and the scope of the project was relatively narrow, this represents an important first step in creating an effective venue to promote student voice - particularly in large classes. Instructors have already commented on several changes they have made after attending the student-faculty discussion, to include changes to allow more flexible use of technology in the classroom as well as including more opportunities for small group engagement. The next stage of this project will be carried out over the 20142015 academic year and will include twice the number of students and will incorporate additional sessions with faculty.

As this study continues, additional consideration should be given to student feedback not just about their experiences in large classes, but about the focus group as well, seeking to better understand the student perspective of the focus group experience. Feedback from faculty should also be solicited, again in an effort to more fully understand how focus groups might be used to effectively engage students and faculty in a collaborative dialogue. In some large classes, an instructor might find it useful to form a focus group early in the semester as a way to build a 
continuing discussion about the course and empowering student voice. Where time or other constraints make individual course focus groups infeasible, university-wide focus groups centred around a key theme, such as on the topic of large classes as in this pilot study, represent an effective way to enhance student voice and provide a venue for faculty to listen.

\section{References}

Breen, R. L. (2006) 'A practical guide to focus-group research'. Journal of Geography in Higher Education. 30 (3): 463-475. http://dx.doi.org/10.1080/03098260600927575

Fielding, M. (2001) 'Beyond the rhetoric of student voice: New departures or new constraints in the transformation of 21 st century schooling?'. Forum for Promoting 3-19 Comprehensive Education. 43 (2): 100-110. http://dx.doi.org/10.2304/forum.2001.43.2.1

Fitzgerald, R. and Corazzo, P. (2013) 'Out of sight, out of mind: Capturing the distance (online) learner experience’. Enhancing the Learner Experience in Higher Education. 5 (1): 58-64. http://dx.doi.org/10.14234/elehe.v5i1.76

Fluckiger, J., Vigil, Y. T. Y., Pasco, R., and Danielson, K. (2010) 'Formative feedback: Involving students as partners in assessment to enhance learning'. College Teaching. 58 (4): 136140. http://dx.doi.org/10.1080/87567555.2010.484031

Giles, A., Martin, S. C., Bryce, D., and Hendry, G. D. (2004) 'Students as partners in evaluation: Student and teacher perspectives'. Assessment \& Evaluation in Higher Education. 29 (6): 681685. http://dx.doi.org/10.1080/0260293042000227227

Hamilton, D. M., Pritchard, R. E., Welsh, C. N., Potter, G. C., and Saccucci, M. S. (2002) 'The effects of using in-class focus groups on student course evaluations'. Journal of Education for Business. 77 (6): 329-333. http://dx.doi.org/10.1080/08832320209599684

Hendershott, A. and Wright, S. (1993) 'Student focus groups and curricular review'. Teaching Sociology. 21 (2): 154-159.

Kramer, M. W. \& Pier, P. M. (1997). 'A holistic examination of students' perceptions of effective and ineffective communication by college teachers'. Paper presented at the Annual Meeting of the National Communication Association. (83rd. Chicago, IL, November 19-23, 1997).

Little, B. and Williams, R. (2010) 'Students' roles in maintaining quality and in enhancing learning: Is there a tension?’ Quality in Higher Education. 16 (2): 115-127. http://dx.doi.org/10.1080/13538322.2010.485740

Marsh, H. W. (1984) 'Students' evaluations of university teaching: Dimensionality, reliability, validity, potential baises, and utility'. Journal of Educational Psychology. 76 (5): 707-754. http://dx.doi.org/10.1037/0022-0663.76.5.707 
Secor, A. J. (2010) Social surveys, interviews, and focus groups. In Gomez, B. and Jones III, J. P. (eds) Research Methods in Geography: A Critical Introduction. West Sussex: Blackwell Publishing, Ltd.

University of Mary Washington. 2010. 'Mission Statement'. Available online:

http://www.umw.edu/about/mission/ (accessed 1/8/14).

Wachtel, H. K. (1998) 'Student evaluation of college teaching effectiveness: A brief review' Assessment \& Evaluation in Higher Education. 23 (2): 191.

http://dx.doi.org/10.1080/0260293980230207

Williams, W. M. and Ceci, S. J. (1997) “"How'm I Doing?” Problems with student ratings of instructors and courses'. Change: The Magazine of Higher Learning. 29 (5): 12-23.

http://dx.doi.org/10.1080/00091389709602331

\section{About the author}

Caitlin C. Finlayson is an Assistant Professor in the Department of Geography at the University of Mary Washington, United States of America.

Email: cfinlay@umw.edu 